\title{
Atmosfera modificada na conservação de alimentos
}

\author{
Modified atmosphere in food preservation
}

\section{Samira Pirola Santos Mantilla ${ }^{[a]}$, Sérgio Borges Mano ${ }^{[b]}$, Helio de Carvalho Vital ${ }^{[c]}$, Robson Maia Franco ${ }^{\text {b] }}$}

[a] Médica veterinária, Doutoranda de Higiene Veterinária e Processamento Tecnológico de Produtos de Origem Animal, Universidade Federal Fluminense (UFF), Niterói, RJ - Brasil, e-mail: samiramantilla@yahoo.com.br

[b] Médico Veterinário, professor Doutor do Departamento de Tecnologia de Alimentos, Universidade Federal Fluminense (UFF), Niterói, RJ - Brasil, e-mail: mtasbm@vm.uff.br; robsonmf@vm.uff.br

[c] Físico, pesquisador Doutor do Centro Tecnológico do Exército (CTEx), Rio de Janeiro, RJ - Brasil, e-mail: vital@ctex.eb.br

\section{Resumo}

A embalagem em atmosfera modificada é um método de conservação de alimentos que proporciona aumento da sua validade comercial, diminui perdas com sua deterioração e facilita a comercialização dos diferentes produtos. Realizou-se uma revisão de literatura sobre tecnologia da embalagem em atmosfera modificada, analisando os seus efeitos sobre os micro-organismos, os riscos associados à sua utilização em alimentos e as misturas gasosas mais utilizadas nos diferentes produtos alimentícios. O efeito bacteriostático da embalagem em atmosfera modificada deve-se à ação do $\mathrm{CO}_{2}$, que aumenta a fase de adaptação e diminui a taxa de crescimento microbiano. A mistura de gases ideal vai depender de vários fatores, como o tipo de alimento, a microbiota presente e o principal mecanismo de deterioração do alimento. Alimentos que não respiram, como carnes e derivados, devem ser embalados com filmes de baixa permeabilidade aos gases, enquanto aqueles que respiram, como frutas e vegetais, devem ser embalados com filmes que possibilitem a troca gasosa. Alguns pesquisadores salientam sobre a possibilidade de risco no consumo de alimentos embalados com atmosfera modificada, porém, mais estudos devem ser realizados para verificar essa real possibilidade.

Palavras-chave: Dióxido de carbono. Conservação de alimentos. Efeito bacteriostático. Filmes de embalagem. 


\begin{abstract}
Modified atmosphere packaging is a method of food preservation that can extend shelf life, thereby reducing losses due to early deterioration and consequently facilitating the commercialization of many types of products. This paper summarizes the findings from a literature review on the technology of modified atmosphere packaging and analyzes its effects as well as related safety issues for different gas mixtures. The bacteriostatic effect of modified atmosphere packaging is usually due to the action of carbon dioxide, which extends the adaptation phase and decreases the rate of microbial growth. The ideal gas mixture for a certain product depends on several factors such as the microflora present, the type of food and the main mechanism of food deterioration. Foods that do not breathe, like meat and meat products must be packaged with films of low permeability to gases, while those that breathe, like fruits and vegetables should be packed with films that allow gas exchange. Some researchers emphasize the possibility of risk in the consumption of foods packaged in modified atmosphere and stress the need for more scientific research on that technology.
\end{abstract}

Keywords: Carbon dioxide. Food preservation. Bacteriostatic effect. Films packaging.

\title{
Introdução
}

A embalagem em atmosfera modificada (EAM) consiste na substituição do ar, no interior da embalagem, por uma mistura de gases como oxigênio $\left(\mathrm{O}_{2}\right)$, dióxido de carbono $\left(\mathrm{CO}_{2}\right)$ e nitrogênio $\left(\mathrm{N}_{2}\right)$ ao redor do produto. $\mathrm{O}$ aumento do prazo comercial deste método de conservação de alimentos deve-se ao efeito inibitório do $\mathrm{CO}_{2}$ sobre os diferentes tipos microbianos e à redução ou remoção do $\mathrm{O}_{2}$ do interior da embalagem.

A estratégia da embalagem sob atmosfera modificada é retardar o crescimento dos micro-organismos patogênicos e deteriorantes presentes, a partir da diminuição da concentração de $\mathrm{O}_{2}$ e da aplicação de níveis elevados de $\mathrm{CO}_{2}$, que possui efeito inibidor do crescimento bacteriano. A modificação da atmosfera no interior da embalagem é determinada pela interação de três processos: respiração do produto, difusão do gás através do produto e permeabilidade do filme aos gases. A difusão do gás é afetada pela temperatura, massa e volume do alimento, taxa de respiração e pela permeabilidade da membrana (LEON, 1999).

A embalagem a vácuo é a primeira forma de EAM desenvolvida comercialmente, sendo empregada amplamente para produtos como cortes de carnes vermelhas frescas, curadas, queijos duros e café moído (PARRY, 1993). Aumentos significativos no prazo comercial de produtos frescos e curados, obtidos com o uso da EAM, têm reduzido perdas por deterioração precoce e gerado aumento da distribuição de produtos de alta qualidade. Misturas gasosas são usadas com $\mathrm{CO}_{2}, \mathrm{~N}_{2}$ e $\mathrm{O}_{2}$, em uma variedade de combinações, podendo ser com alta concentração de $\mathrm{O}_{2}(80 \%)$ ou baixa $(16 \%)$, nas quais o $\mathrm{N}_{2}$ é usado como um gás de enchimento combinado com uma determinada proporção de $\mathrm{CO}_{2}$ que inibe os micro-organismos. Estes sistemas usam filmes de embalagem com barreira ao $\mathrm{O}_{2}$ e quase sempre essas embalagens são mantidas durante a estocagem e distribuição a $4{ }^{\circ} \mathrm{C}$ (HOLLEY; GILL, 2005).

Este artigo de revisão teve como objetivo estudar a tecnologia de EAM, enfatizando a importância da sua utilização na preservação de alimentos e seus benefícios verificados por diversos autores em diferentes tipos de alimentos, avaliando o efeito sobre os micro-organismos e sobre o prazo comercial dos produtos alimentícios.

\section{Definição e tecnologia da EAM}

A embalagem a vácuo é definida como o acondicionamento do produto em embalagens com barreira aos gases nas quais o ar é removido para prevenir o crescimento de organismos deteriorantes, a oxidação e a descoloração do produto. De acordo com a maioria dos pesquisadores, esse tipo de embalagem é considerado uma forma de EAM, visto que, ao remover o ar, a atmosfera no interior da embalagem é modificada. Sob estas 
condições, o $\mathrm{O}_{2}$ residual é utilizado pela microbiota aeróbica residente, produzindo $\mathrm{CO}_{2}(10-20 \%)$ e fazendo com que o potencial redox tenda a ficar negativo. Estas mudanças no potencial redox e na composição da atmosfera suprimem o crescimento de bactérias aeróbias deteriorantes que produzem a viscosidade, rancificação e descoloração indesejáveis no produto. A condição resultante favorece o crescimento de organismos anaeróbios facultativos incluindo as bactérias ácido-láticas, porém em velocidadelenta, atrasando a deterioração da carne (HINTLIAN; HOTCHKISS, 1986, GENIGEORGIS, 1895). Segundo Church (1995), a embalagem a vácuo possui a vantagem de ser uma técnica simples, porém, a compressão que causa no alimento pode diminuir sua forma original e/ou aumentar o exsudato da carne.

A embalagem em atmosfera modificada (EAM) é um método que implica a eliminação do ar no interior do envase e sua substituição por um gás, ou mistura de gases, dependendo do tipo de produto. A atmosfera gasosa se altera continuamente durante todo o período de armazenamento graças à influência de diversos fatores, como a respiração do produto envasado, mudanças bioquímicas e a lenta difusão dos gases através do alimento (PARRY, 1993).

Sob boas condições de vácuo, o nível de $\mathrm{O}_{2}$ reduz para menos de $1 \%$. No caso da embalagem de carnes a vácuo, a respiração da carne rapidamente consome o $\mathrm{O}_{2}$ residual, substituindo-o por $\mathrm{CO}_{2}$, que eventualmente aumenta para 10-20\% na embalagem. Infelizmente, a embalagem a vácuo de carnes vermelhas é inadequada para o mercado varejista, porque a depleção do $\mathrm{O}_{2}$ associada à baixa permeabilidade do filme ao $\mathrm{O}_{2}$ causa mudança na cor de vermelho para marrom, em virtude da conversão da mioglobina em metamioglobina. Outra desvantagem é o acúmulo de exsudato durante o armazenamento prolongado das carnes embaladas a vácuo (BLAKISTONE, 1999).

Os objetivos da EAM são estender o prazo comercial de produtos alimentícios e prevenir (ou pelo menos retardar) qualquer alteração indesejável nas características sensoriais, nutritivas e microbiológicas nos alimentos. EAM atinge seus objetivos baseados em três princípios: redução de alterações fisiológicas, químicas/bioquímicas e físicas indesejáveis nos alimentos; controle do crescimento microbiano e prevenção da contaminação do produto (FLOROS; MATSOS, 2005).

A modificação da atmosfera no interior da embalagem pode ser conseguida mediante mecanismos ativos ou passivos. A modificação ativa envolve duas técnicas diferentes: gás flushing e vácuo compensado. As modificações passivas, no caso de frutas e vegetais, ocorrem como consequência da respiração ou do metabolismo de micro-organismos associados com o alimento. A estrutura da embalagem normalmente é constituída por um filme polimérico e a permeabilidade dos gases através do filme também influencia a composição da atmosfera que se desenvolve (BLAKISTONE, 1999; ROBERTSON, 2006).

Na técnica do gás flushing ou de nivelamento do gás, o gás é introduzido continuamente na embalagem diluindo o ar presente, sendo, no fim, a embalagem selada. $\mathrm{Na}$ técnica do vácuo compensado ocorre a passagem do produto por uma bandeja e remoção do ar. O vácuo é rompido pela mistura de gases apropriada e a embalagem é selada com calor. A vantagem deste último método é a maior eficiência na remoção do $\mathrm{O}_{2}$ a níveis residuais menores que 1\% (SMITH et al., 1990).

$\mathrm{Na}$ técnica do gás flushing existe um limite de eficiência do sistema, pois a substituição do ar na embalagem é efetuada pela diluição. Na embalagem ficam 2-5\% de $\mathrm{O}_{2}$ residual, assim, essa técnica não é adequada para embalar alimentos muito sensíveis ao $\mathrm{O}_{2}$. A maior vantagem do processo de gás flushing é a velocidade, visto que a operação é contínua. No caso do vácuo compensado, como são realizados dois processos a velocidade é um pouco mais lenta, entretanto, a eficiência com respeito ao $\mathrm{O}_{2}$ residual é muito superior à técnica do gás flushing (BLAKISTONE, 1999).

O princípio de conservação de vegetais por meio de EAM é diferente daqueles produtos que não respiram, como carne, massas e queijos, pois diferentemente dos outros alimentos, estes produtos continuam respirando após a colheita e durante a sua comercialização (SARANTÓPOULOS, 1997). Depois do processo de embalagem, as frutas e hortaliças consomem $\mathrm{O}_{2}$ e produzem $\mathrm{CO}_{2}$ e vapor d'água. Se houver um equilíbrio entre o $\mathrm{O}_{2}$ e o $\mathrm{CO}_{2}$ no interior da embalagem, poder-se-á criar, de forma passiva, uma atmosfera modificada favorável (PARRY, 1993). Um equilíbrio de 2-5\% de $\mathrm{O}_{2}$ e 3-8\% de $\mathrm{CO}_{2}$ demonstrou um atraso na maturação e no amolecimento de vegetais e reduziu a degradação da clorofila e a deterioração microbiana (BLAKISTONE, 1999).

Rev. Acad., Ciênc. Agrár. Ambient., Curitiba, v. 8, n. 4, p. 437-448, out./dez. 2010 
No caso dos alimentos que respiram, a tecnologia de embalagem é conhecida como modificação passiva da atmosfera e visa a retardar a respiração, o amadurecimento, a senescência, a perda de clorofila, a perda de umidade, o escurecimento enzimático e, consequentemente, as alterações de qualidade advindas destes processos. Atmosferas com 3-8\% de $\mathrm{O}_{2}$ e 3-10\% de $\mathrm{CO}_{2}$ têm potencial para aumentar o prazo comercial destes produtos (SARANTÓPOULOS, 1997).

\section{Gases e filmes utilizados na EAM}

De acordo com Church (1994), geralmente são utilizados três gases para alimentos: $\mathrm{O}_{2}, \mathrm{~N}_{2}$ e $\mathrm{CO}_{2}$, cada qual possuindo uma função específica $(\mathrm{CHURCH}, 1995)$. A escolha da mistura de gases utilizada é influenciada pela microbiota capaz de crescer no produto, pela sensibilidade do produto ao $\mathrm{O}_{2}$ e ao $\mathrm{CO}_{2}$ e pela estabilidade da cor desejada (por exemplo: preservação da oximioglobina em carne fresca e nitrosomioglobina em produtos cárneos curados).

Parry (1993) salienta que outros gases, como o cloro, óxido de etileno, dióxido de $\mathrm{N}_{2}$, ozônio, óxido de propileno e dióxido de enxofre, também têm sido analisados experimentalmente para a embalagem em atmosfera modificada, porém é pouco provável que as autoridades aprovem a sua utilização comercial para o envase de alimentos.

$\mathrm{O}$ gás $\mathrm{O}_{2}$ geralmente estimula o crescimento de bactérias aeróbicas e inibe o crescimento de anaeróbias estritas, embora exista uma grande variação da sensibilidade de anaeróbios ao $\mathrm{O}_{2}$. A presença de $\mathrm{O}_{2}$ é mais importante no armazenamento de carnes frescas por manter o pigmento da carne, mioglobina em sua forma oxigenada, oximioglobina, que fornece à carne fresca a cor vermelha característica. Baixos níveis de $\mathrm{O}_{2}$ $(0,5 \%)$ podem ocasionar uma coloração marrom em carnes resfriadas $(\mathrm{CHURCH}, 1994)$.

Além disso, o $\mathrm{O}_{2}$ é responsável por muitas reações indesejadas nos alimentos, incluindo oxidação e rancificação de gorduras e óleos, rápido amadurecimento e senescência de frutas e vegetais, alterações na cor e deterioração ocasionada pelo crescimento de bactérias aeróbias. Graças aos efeitos negativos citados, o $\mathrm{O}_{2}$ é geralmente evitado na EAM de vários produtos. Entretanto, sua presença em pequenas quantidades é necessária para alguns produtos. Por exemplo, em muitas frutas e vegetais, para permitir seus processos básicos de respiração aeróbia; em carnes vermelhas, para manter a cor vermelha das carnes frescas (FLOROS; MATSOS, 2005).

Para a maioria dos produtos embalados em atmosfera modificada, exceto frutas frescas, vegetais e certas carnes, o $\mathrm{O}_{2}$ é excluído ou significativamente reduzido da embalagem. Entretanto, a presença de algum $\mathrm{O}_{2}$ no início pode favorecer o crescimento de microbiota competitiva como bactérias ácido-láticas e, desse modo, ajudar a prevenir o desenvolvimento de alguns patógenos anaeróbicos, principalmente Clostridium botulinum (CHURCH, 1994; OORAIKUL, 2003).

Alguns pesquisadores verificaram que altas concentrações de $\mathrm{O}_{2}$ têm sido eficazes na redução da microbiota em diferentes alimentos, como citado por Amanatidou et al. (2000), ao concluírem que altas concentrações de $\mathrm{O}_{2}$ podem ser usadas para conservar cenouras minimamente processadas, pois mantêm seu frescor e diminuem a microbiota durante o armazenamento prolongado. Jacxsens et al. (2001) também observaram que a concentração de $95 \%$ de $\mathrm{O}_{2}$ estendeu a fase de adaptação do patógeno Listeria monocytogenes e reduziu a população de leveduras em vegetais prontos para o consumo. Mais recentemente, Strotmann et al. (2008) verificaram que $100 \%$ de $\mathrm{O}_{2}$ na embalagem de carne suína inoculada com Yersinia enterocolitica reduziu significativamente o número desse patógeno ao fim do armazenamento (12 dias).

$\mathrm{O}$ gás $\mathrm{CO}_{2}$ é o principal responsável pelo efeito bacteriostático em EAM. Este efeito é influenciado pela carga bacteriana inicial, pela temperatura de estocagem e pelo tipo de produto embalado. Seu modo de ação depende da dissolução do gás no produto embalado. O efeito inibitório da embalagem em atmosfera modificada é diretamente relacionado com a quantidade de $\mathrm{CO}_{2}$ presente. A solubilidade deste gás é indiretamente proporcional à temperatura de armazenamento, logo baixas temperaturas possuem um efeito sinérgico para a ação bacteriostática do $\mathrm{CO}_{2}(\mathrm{CHURCH}, 1995)$.

Quando o $\mathrm{CO}_{2}$ se dissolve em água, este acidifica o meio. Essa acidificação, assim como o efeito antimicrobiano do $\mathrm{CO}_{2}$ nas concentrações maiores que $10-15 \%$, pode suprimir o crescimento de muitos micro-organismos deteriorantes e, por esta razão, esse é um componente importante da EAM (BRODY,1995). 
$\mathrm{O} \mathrm{CO}_{2}$ é solúvel em água e em gorduras e sua absorção pelo produto causa pequena redução no volume do gás e, consequentemente, pode ocasionar o colapso da embalagem. Em alimentos com muita umidade como carnes vermelhas e de aves, pescados, a excessiva absorção de $\mathrm{CO}_{2}$ pode causar o colapso da embalagem, fazendo com que o produto fique com uma leve aparência de embalagem a vácuo. Além disso, embalagens contendo altas concentrações de $\mathrm{CO}_{2}$ podem ocasionar o aumento do exsudato em carne fresca (CHURCH, 1994; CHURCH, 1995).

$\mathrm{O} \mathrm{N}_{2}$ é um gás quimicamente inerte, insípido e menos predisposto a acidentes do que os outros gases comumente usados em EAM. $\mathrm{O} \mathrm{N}_{2}$ é usado como um gás de enchimento, substituindo o $\mathrm{O}_{2}$ como uma alternativa da embalagem a vácuo, visto que, por ser pouco solúvel em água e gordura, é utilizado para limitar o colapso da embalagem causado pela absorção do $\mathrm{CO}_{2}$ pelo produto. Além disso, retarda a rancificação oxidativa e inibe o crescimento de micro-organismos aeróbios (CHURCH, 1995; BLAKISTONE, 1999).

A mistura de gases utilizada em EAM de diferentes alimentos depende da natureza do alimento e dos mecanismos prováveis de deterioração. Quando a deterioração é principalmente microbiana, o nível de $\mathrm{CO}_{2}$ na mistura deve ser o mais alto possível, limitado somente pelos efeitos negativos do $\mathrm{CO}_{2}$ no alimento específico (por exemplo, colapso da embalagem). A composição gasosa típica nessa situação é de $30 \%$ a $60 \%$ de $\mathrm{CO}_{2}$ e $40 \%$ a $70 \%$ de $\mathrm{N}_{2}$. Para produtos que são muito sensíveis ao $\mathrm{O}_{2}$, nos quais a deterioração ocorre principalmente pela rancificação oxidativa, misturas de $100 \% \mathrm{~N}_{2}$ ou $\mathrm{N}_{2} / \mathrm{CO}_{2}$ (se a deterioração microbiana também for importante nesse alimento) são usadas. Para produtos que respiram, é importante evitar também alta concentração de $\mathrm{CO}_{2}$ ou concentração muito baixa de $\mathrm{O}_{2}$ (para evitar a respiração anaeróbica) (ROBERTSON, 2006).

Em relação aos materiais de envase, esses devem contemplar as seguintes propriedades físicas essenciais: baixa transmissão de vapor de água, elevada capacidade de barreira ante os gases, resistência mecânica aos esforços sofridos durante o manejo da máquina e alta capacidade de proporcionar a integridade da vedação que assegure a retenção do gás desde o envase até que seja aberto pelo consumidor (HASTINGS, 1993).

Entre os filmes comumente empregados para a EAM incluem-se: policloreto de vinila, polipropileno, poliestireno, nylon e o polietileno, em que as suas propriedades de barreiras dependem da espessura. O polietileno de baixa densidade é utilizado em vários plásticos por ser muito versátil, porém sua permeabilidade é moderadamente baixa para o vapor de água, mas alta para o $\mathrm{O}_{2}$; também apresenta um reduzido efeito de barreira contra os odores. O polipropileno é quimicamente similar ao polietileno e pode ser extrusado ou coextrusado para proporcionar características de vedação pelo calor. Proporciona maior barreira aos gases e ao vapor de água do que o polietileno. O policloreto de vinila (PVC) é o filme termoformável mais utilizado para embalagens em atmosfera modificada, pois possui uma boa capacidade de barreira diante dos gases e moderada ante o vapor de água, alem de excelente resistência a gorduras (GREENGRAS, 1993).

O polietireno é um polímero termoplástico claro com elevada resistência à extensão, mas com propriedades de barreira reduzidas. Os nylons são filmes resistentes com elevada resistência à extensão, mas são higroscópicos e suas propriedades mecânicas se alteram graças à absorção de água. Por sua vez, o nylon, por possuir maior resistência, é recomendado para uso em produtos cárneos com possibilidade de conter ossos afiados (GREENGRAS, 1993).

Um filme adequado para a embalagem deve ser escolhido baseado na natureza do produto que será embalado. Alimentos que requerem a exclusão de gases como $\mathrm{O}_{2} \mathrm{e} / \mathrm{ou}$ alta retenção de gases como $\mathrm{CO}_{2}$ devem ter permeabilidade muito baixa a esses gases. Produtos frescos, por outro lado, requerem certa quantidade de $\mathrm{O}_{2}$ para manter as atividades fisiológicas, como a respiração e o amadurecimento. Como carnes vermelhas necessitam de $\mathrm{O}_{2}$ para manter a coloração avermelhada, o material da embalagem deve ser seletivamente permeável ao $\mathrm{O}_{2}$, ao $\mathrm{CO}_{2}$ e ao vapor de água, para permitir adequada difusão do $\mathrm{O}_{2}$ dentro da embalagem, enquanto previne a perda excessiva de $\mathrm{CO}_{2}$ e de vapor de água no interior da invólucro (OORAIKUL, 2003).

\section{Efeito sobre os micro-organismos}

A extensão da validade comercial do produto embalado em atmosfera modificada ocorre graças à baixa concentração de $\mathrm{O}_{2}$, resultando no controle de bactérias aeróbias, que são as principais responsáveis pela deterioração. Além disso, a alta concentração de $\mathrm{CO}_{2}$ também aumenta a validade comercial dos alimentos

Rev. Acad., Ciênc. Agrár. Ambient., Curitiba, v. 8, n. 4, p. 437-448, out./dez. 2010 
embalados. O efeito antimicrobiano do $\mathrm{CO}_{2}$ ocorre em concentração igual ou acima de 10\%, aumentando conforme se eleva sua concentração na embalagem. Usando $20 \%$ de $\mathrm{CO}_{2}$, é possível controlar o crescimento de muitos aeróbios, incluindo Pseudomonas spp., Acenatobacter spp. e Moraxella spp., contudo, altas concentrações podem estimular o crescimento de C. botulinum (FLOROS; MATSOS, 2005).

Embora o mecanismo da atividade antimicrobiana do $\mathrm{CO}_{2}$ não esteja completamente entendido, sabe-se que o $\mathrm{CO}_{2}$ estende a fase de retardo do crescimento microbiano de muitas maneiras: penetra na parede da célula microbiana e altera a permeabilidade celular; solubiliza-se dentro da célula e produz ácido carbônico $\left(\mathrm{H}_{2} \mathrm{CO}_{3}\right)$, que reduz o $\mathrm{pH}$ da célula e, finalmente, interfere em muitos caminhos enzimáticos e bioquímicos dentro da célula microbiana, reduzindo a sua taxa de crescimento (FLOROS; MATSOS, 2005).

Segundo Jay (2005), existem duas explicações para o mecanismo de inibição do $\mathrm{CO}_{2}$ sobre os microorganismos. $\mathrm{O} \mathrm{CO}_{2}$ bloqueia o metabolismo e parece afetar a descarboxilação enzimática e a permeabilidade da membrana celular. $\mathrm{O} \mathrm{CO}_{2}$ se dissolve na forma de ácido carbônico, que por sua vez vai ocasionar mudanças na permeabilidade celular.

Concentrações de $\mathrm{CO}_{2}$ em torno de 5\% inibem o crescimento da maioria das bactérias deteriorantes, especialmente espécies psicrotróficas, que podem crescer em diferentes alimentos refrigerados. Diversos mecanismos para a ação do $\mathrm{CO}_{2}$ sobre os micro-organismos têm sido identificados: alteração da função da membrana celular, incluindo efeitos na captação de nutrientes e sua absorção; inibição direta de enzimas ou diminuição na taxa das reações enzimáticas; penetração na membrana celular, levando a alterações intracelulares de $\mathrm{pH}$; alterações diretas nas propriedades físico-químicas de proteínas. Uma provável combinação dessas atividades é responsável pelo efeito bacteriostático do $\mathrm{CO}_{2}$ (BLAKISTONE, 1999).

A atividade inibitória do $\mathrm{CO}_{2}$ aumenta se a temperatura de armazenamento diminui em virtude da maior solubilidade do gás em água sob baixas temperaturas. A inibição também aumenta quando o pH diminui em uma faixa ácida (JAY, 2005). A efetividade do $\mathrm{CO}_{2}$ depende também da fase de crescimento do organismo presente. $\mathrm{O} \mathrm{CO}_{2}$ aumenta a duração da fase de adaptação e reduz a taxa de crescimento durante a fase logarítmica. Entretanto, o efeito sobre a primeira é maior e, portanto, à medida que a bactéria passa da fase de adaptação para a fase log, o efeito inibitório do crescimento é reduzido (CHURCH, 1995).

Em geral, as bactérias Gram negativas são mais sensíveis à inibição pelo $\mathrm{CO}_{2}$ do que as Gram positivas, sendo as pseudomonas classificadas como as mais sensíveis, e os clostrídios, como os mais resistentes. Em carnes, durante o armazenamento prolongado, o $\mathrm{CO}_{2}$ provoca uma mudança considerável em sua microbiota, variando de uma microbiota predominantemente formada por micro-organismos Gram negativos, nos produtos frescos, para uma principalmente, ou exclusivamente, formada por Gram positivos (JAY, 2005).

Fungos, leveduras e bactérias aeróbias deteriorantes são altamente suscetíveis ao $\mathrm{CO}_{2}$. As bactérias facultativas podem ou não ser inibidas pelo $\mathrm{CO}_{2}$, enquanto as bactérias ácido-láticas e anaeróbias são altamente resistentes (FINNE, 1982)

Bactérias, como as da espécie Brochothrix thermosphacta, podem tolerar níveis de $\mathrm{CO}_{2}$ acima de $75 \%$, e outras, como as bactérias ácido-láticas, podem crescer em 100\% de $\mathrm{CO}_{2}$ (SMITH et al., 1990).

\section{Influência da EAM na extensão da validade comercial}

\section{Carne e derivados}

Carnes são alimentos muito perecíveis e o principal limitante de sua validade comercial é o crescimento microbiano. Deste modo, atmosferas contendo alta concentração de $\mathrm{CO}_{2}$ devem ser usadas para suprimir os micro-organismos e estender a validade do produto. Uma mistura de gases com altas concentrações de $\mathrm{O}_{2}$ e $\mathrm{CO}_{2}$ é ideal para a conservação da qualidade dos produtos cárneos e a extensão do prazo comercial (FLOROS; MATSOS, 2005).

De um modo geral, a validade comercial de carnes vermelhas pode ser aumentada para até dois meses se embaladas com $75 \%$ de $\mathrm{O}_{2}+25 \%$ de $\mathrm{CO}_{2}$ e armazenadas a $-1{ }^{\circ} \mathrm{C}$. A alta concentração de $\mathrm{O}_{2}$ garante a manutenção da cor vermelha (JAY, 2005).

Rev. Acad., Ciênc. Agrár. Ambient., Curitiba, v. 8, n. 4, p. 437-448, out./dez. 2010 
Comercialmente, o sistema de embalagem em atmosfera modificada mais utilizado para embalagem da carne fresca emprega altas concentrações de $\mathrm{O}_{2}$ em combinação com $\mathrm{CO}_{2}$, normalmente $60-80 \% \mathrm{O}_{2}$ e 20-40\% $\mathrm{CO}_{2}$ (EILERT, 2005). Segundo Pereira (2005), a proporção de misturas de gases mais utilizada para carnes vermelhas é aproximadamente $70 \% \mathrm{O}_{2}$ e $30 \% \mathrm{CO}_{2}$. Porém, a estabilidade da cor da carne e a validade comercial dos produtos armazenados contendo esta mistura de gases ainda não foram definidas.

Conceição (2002) verificou que a EAM $\left(80 \% \mathrm{O}_{2} / 20 \% \mathrm{CO}_{2}\right)$ aumentou a validade comercial de carne moída bovina em sete a dez dias quando estocada entre $0-3{ }^{\circ} \mathrm{C}$.

Em relação à carne suína, Mano et al. (2002) relataram que a validade comercial da carne foi aumentada quando esta foi embalada em atmosfera modificada e na combinação de altas concentrações de $\mathrm{CO}_{2}$ em temperaturas mais baixas $\left(1{ }^{\circ} \mathrm{C}\right)$. O maior prazo comercial (> 54 dias) foi obtido com a mistura de 40\%/60\% $\mathrm{CO}_{2} / \mathrm{O}_{2}$ e armazenamento a $1{ }^{\circ} \mathrm{C}$.

Rosa (2009) concluiu que, do ponto de vista microbiológico, as três composições gasosas estudadas $\left(75 \% \mathrm{O}_{2}+25 \% \mathrm{CO}_{2} ; 50 \% \mathrm{O}_{2}+50 \% \mathrm{CO}_{2}\right.$ e $\left.100 \% \mathrm{CO}_{2}\right)$ conservaram bifes de lombo suíno por até 15 dias de armazenamento, porém, somente as atmosferas com altas concentrações de $\mathrm{O}_{2}(>50 \%)$ garantiram a preservação da cor e da aparência geral dos bifes.

No caso de carne de aves, a presença do $\mathrm{O}_{2}$ não é necessária. Às vezes, no caso de carne de peru, a presença do $\mathrm{O}_{2}$ pode até ser prejudicial, porque causa odores indesejáveis. A extensão da validade comercial de carne de aves sob EAM aumenta com o aumento da concentração de $\mathrm{CO}_{2}$, graças à supressão do crescimento microbiano. Entretanto, tem sido observado que altas concentrações de $\mathrm{CO}_{2}$ podem ocasionar a descoloração do produto (FLOROS; MATSOS, 2005).

De acordo com Jay (2005), o alto pH inicial da carne de frango é o principal fator responsável pelo fato de este produto não ter uma validade comercial tão extensa quanto a carne vermelha.

Para aves, diferentes misturas gasosas são utilizadas no seu acondicionamento, podendo combinar $\mathrm{O}_{2} / \mathrm{CO}_{2} ; \mathrm{N}_{2} / \mathrm{CO}_{2}$ e $\mathrm{O}_{2} / \mathrm{CO}_{2} / \mathrm{N}_{2}$. No acondicionamento de carcaças de aves podem-se utilizar misturas com altas concentrações de $\mathrm{CO}_{2}$, atingindo uma vida útil de até 21 dias (normalmente 6 a 14 dias). Para a comercialização de cortes em pequenas porções, a concentração de $\mathrm{CO}_{2}$ não deve exceder $30 \%$, para não haver problemas de descoloração (ZEPKA, 2009).

Jiménez et al. (1997) observaram que a $\operatorname{EAM}\left(70 \% \mathrm{CO}_{2} / 30 \% \mathrm{~N}_{2}\right)$ estendeu a validade comercial de peito de frango resfriado para 21 dias, quando comparada aos 5 dias de validade em embalagem sob ar atmosférico.

No trabalho desenvolvido por Saucier et al. (2000), foi avaliado o prazo comercial de carnes de frango e de peru embaladas sob dois tipos de atmosfera modificada: $62 \% \mathrm{CO}_{2} / 8 \% \mathrm{O}_{2} / 30 \% \mathrm{~N}_{2}$ e $20 \% \mathrm{CO}_{2} / 80 \%$ $\mathrm{N}_{2}$. As carnes embaladas com a segunda mistura de gases mantiveram a contagem microbiana mais elevada durante todo o experimento, porém nenhuma das misturas garantiu a inocuidade dos produtos.

Patsias et al. (2006) verificaram que as carnes de frango pré-cozidas foram melhor conservadas sob as misturas de gases: 60\%/40\% e 90\%/10\% $\left(\mathrm{CO}_{2} / \mathrm{N}_{2}\right)$. A validade comercial foi estendida por mais seis dias quando comparada com o controle embalado a vácuo, e essas misturas mantiveram as características de odor e sabor desejáveis.

O interesse do uso da EAM em peixes tem relação com o fato de serem encontradas linhagens de $C$. botulinum não proteolíticas na água, as quais podem crescer em temperaturas menores que $4{ }^{\circ} \mathrm{C}$. Além disso, o pH dos frutos do mar é geralmente maior e mais favorável ao desenvolvimento de patógenos (JAY, 2005).

A composição da atmosfera na embalagem de peixes depende da quantidade de sua gordura. Em geral, uma atmosfera de $30 \% \mathrm{O}_{2}, 40 \% \mathrm{CO}_{2}$ e $30 \% \mathrm{~N}_{2}$ é usada para peixes magros. Uma quantidade elevada de $\mathrm{O}_{2}$ contribui para a extensão da validade comercial de peixes marinhos, pela redução de óxido de trimetilamina (TMAO), um osmo-regulador, em trimetilamina (TMA) (DEVLIEGHERE et al., 2002). TMA é o principal componente responsável pelo odor desagradável do pescado. Entretanto, em se tratando de peixes gordurosos e defumados, a exclusão do $\mathrm{O}_{2}$ é recomendada para evitar a reação oxidativa e o desenvolvimento de ranço. Uma mistura de gases com 60\% $\mathrm{CO}_{2}$ e 40\% $\mathrm{N}_{2}$ é recomendada (FLOROS; MATSOS, 2005).

Ordoñez et al. (2000) concluíram que a embalagem com $40 / 60 \% \mathrm{CO}_{2} / \mathrm{O}_{2}$ de filé de merluza sob refrigeração aumentou a validade do produto em até três vezes. Salgado (2006) verificou que a embalagem $\operatorname{com} 80 \% \mathrm{CO}_{2} / 20 \% \mathrm{~N}_{2}$ foi a mais indicada para a estocagem de pargo, pois com essa atmosfera houve maior extensão da validade comercial e manutenção da qualidade desse pescado. 


\section{Frutas e vegetais}

A diferença das frutas e vegetais para outros produtos perecíveis refrigerados embalados em atmosfera modificada é que essas continuam respirando após a colheita. Os produtos da respiração aeróbia são $\mathrm{CO}_{2} \mathrm{e}$ o vapor de água, enquanto que os produtos da fermentação, tais como etanol, acetaldeido e ácidos orgânicos, são produzidos durante a respiração anaeróbia. Se o alimento está embalado em um filme impermeável, os níveis de $\mathrm{O}_{2}$ no interior da embalagem poderiam diminuir a concentrações muito baixas, iniciando-se a respiração anaeróbia, com o acúmulo dos produtos resultantes dessa respiração. O etanol, o acetaldeído e os ácidos orgânicos normalmente estão relacionados com odores e sabores desagradáveis e com a deterioração do produto. Além disso, nessas condições, haverá o risco de crescimento de patógenos anaeróbios como C. botulinum. Assim, recomenda-se um mínimo de 2-3\% de $\mathrm{O}_{2}$. Se o filme possui alta permeabilidade, haverá pouca ou nenhuma alteração na atmosfera no interior da embalagem e a perda da umidade poderia provocar perda da qualidade das frutas e vegetais pelo murchamento e perda de frescor. Nesse caso, o filme indicado é de permeabilidade intermediária, que permite um equilíbrio na atmosfera (DAY, 1993).

Para obter uma atmosfera estável em embalagens de vegetais frescos, as seguintes condições de equilíbrio devem ser alcançadas: a intensidade da absorção do $\mathrm{O}_{2}$ pelo produto deve ser igual à quantidade total de $\mathrm{O}_{2}$ que escapa através do plástico; a intensidade de emissão de $\mathrm{CO}_{2}$ pelo produto deve se igual à quantidade total de $\mathrm{CO}_{2}$ que escapa através do plástico; a intensidade da respiração do produto junto com a permeabilidade do filme, temperatura e umidade relativa são fatores que determinam o equilíbrio do $\mathrm{CO}_{2} \mathrm{e}$ $\mathrm{O}_{2}$ dentro da embalagem (RIQUELME et al., 1994).

O principal objetivo da atmosfera modificada aplicada a frutas e vegetais é minimizar a taxa de respiração desses produtos. Isso inclui a supressão da produção do gás etileno, responsável pela aceleração do amadurecimento, deterioração e aceleração da senescência em frutas e vegetais. A redução dos níveis de $\mathrm{O}_{2}$ e o aumento do $\mathrm{CO}_{2}$ na atmosfera em volta de produtos frescos apresentam vários efeitos positivos, pois abrandam a respiração e promovem a retenção de clorofila e outros pigmentos. Além disso, como nos outros produtos, níveis elevados de $\mathrm{CO}_{2}$ reduzem a taxa de crescimento microbiano (FLOROS; MATSOS, 2005).

Vilas Boas et al. (2004) observaram que a atmosfera modificada ativa contendo $2 \% \mathrm{O}_{2}+10 \% \mathrm{CO}_{2}$ foi mais eficaz do que a atmosfera com $5 \% \mathrm{O}_{2}+5 \% \mathrm{CO}_{2}$ no controle da atividade respiratória, mostrando-se mais apropriada para a conservação de melões.

Fantuzi et al. (2004) constataram que o repolho minimamente processado apresentou-se em condições adequadas de consumo aos 20 dias de estocagem, a $1{ }^{\circ} \mathrm{C}$ e $5{ }^{\circ} \mathrm{C}$, nas EAM passivas com filmes de alta permeabilidade ao $\mathrm{O}_{2}$. Quando acondicionado em bandejas plásticas transparentes, seladas com filme de PVC termoencolhível, o produto apresentou, no $20^{\circ}$ dia, a $5{ }^{\circ} \mathrm{C}$, características sensoriais indesejáveis.

Santos et al. (2005) concluíram que o abacaxi 'Pérola' minimamente processado pode ser armazenado por oito dias, a $5{ }^{\circ} \mathrm{C}$, sob atmosfera modificada passiva $\left(5 \% \mathrm{O}_{2}+5 \% \mathrm{CO}_{2}, 2 \% \mathrm{O}_{2}+10 \% \mathrm{CO}_{2}\right)$.

Roversi e Marssom (2004) verificaram que a influência da atmosfera modificada $\left(10 \% \mathrm{CO}_{2} / 5 \% \mathrm{O}_{2} \mathrm{e}\right.$ $15 \% \mathrm{CO}_{2} / 5 \% \mathrm{O}_{2}$ ) no crescimento de micro-organismos não foi relevante. Entretanto, a tecnologia da EAM reduziu as taxas de respiração e, consequentemente, minimizou as perdas de qualidade sensorial da alface durante todo o armazenamento. A validade da alface em atmosfera modificada foi estendida em até cinco dias além daquela alcançada pela alface acondicionada em atmosfera natural.

A atmosfera modificada passiva, aliada à refrigeração e às boas práticas de fabricação, foi suficiente para prolongar a validade comercial de mandioquinhas-salsas minimamente processadas, preservando seus atributos de qualidade (NUNES et al., 2009).

\section{Riscos potenciais de alimentos EAM}

Atualmente tem sido levantada a questão da segurança microbiológica no consumo de alimentos em embalagens com atmosfera modificada, visto que hoje esse sistema está sendo aplicado não só para produtos 
frescos, que posteriormente serão submetidos à cocção, como também para produtos pré-processados, de baixa acidez, que serão consumidos apenas após um leve aquecimento (ZEPKA, 2009).

Segundo Church (1994), as autoridades e algumas indústrias de alimentos vêm tendo interesse no perigo que certos alimentos embalados em EAM podem representar para a saúde coletiva. Em relação à segurança microbiológica, o C. botulinum representa um perigo em potencial para alimentos embalados em EAM. Sugere-se que a supressão da microbiota deteriorante em EAM pode resultar em produtos contendo um grande número de micro-organismos patogênicos ou toxinas enquanto a aparência do produto ainda permanece intacta, sendo aceitável sensorialmente pelos consumidores.

A presença de ar em alimentos embalados permite o crescimento de organismos aeróbios deteriorantes. Após o crescimento desses micro-organismos, o produto é provavelmente descartado graças à sua aparência, odor, cor e viscosidade desagradáveis, ainda que esteja livre de patógenos. Em produtos embalados sob atmosfera modificada, a ausência de $\mathrm{O}_{2}$ pode favorecer o crescimento de patógenos anaeróbios facultativos e/ou anaeróbios estritos mais do que os aeróbios deteriorantes. Fato similar pode ocorrer com alimentos irradiados, em que algumas doses de radiação eliminam os deteriorantes, mas não afetam os esporos de C. botulinum (ZURER, $1986^{1}$ apud HINTLIAN, HOTCHKISS, 1986).

Como regra geral, alimentos sujeitos à EAM devem possuir pelo menos um dos itens antibotulínicos seguintes: possuir atividade de água menor que 0,93; ter $\mathrm{pH} 4,6$ ou menor; ser curado com $\mathrm{NaCl}$ ou $\mathrm{NO}_{2}$; conter grande quantidade de não patógenos; ser mantido no estado congelado; ser mantido a $4{ }^{\circ} \mathrm{C}$ ou menos e possuir a validade comercial limitada (inferior a dez dias) (JAY, 2005).

Uma maneira de prevenir o perigo representado pelo $C$. botulinum é o uso de pré-tratamento em combinação com a EAM. O sorbato de potássio, o cloreto de sódio e a irradiação vêm mostrando efetividade (CHURCH, 1994).

Enquanto é fato que elevadas concentrações de $\mathrm{CO}_{2}$ em EAM não inibem o Clostridium sp. em carnes vermelhas, frango ou pescados, não está claro que uma mistura de gases contendo altos níveis desse gás estimule mais o crescimento ou a produção de toxinas do Clostridium sp. do que em embalagens com ar atmosférico (HINTLIAN; HOTCHKISS, 1986). Church (1994) ressalta que a maioria dos estudos reportados pela literatura indica que os riscos de um patógeno de origem alimentar crescer em alimentos sob EAM não é maior, mas sim frequentemente menor do que crescer em alimentos sob armazenamento aeróbico.

Dados disponíveis sugerem que a carne fresca embalada em EAM não proporciona qualquer vantagem competitiva para as bactérias patogênicas crescerem em relação às oportunidades proporcionadas pela carne fresca sem embalagem. O perigo associado à produção de toxina em EAM por C. botulinum, que pode crescer a $3{ }^{\circ} \mathrm{C}$, não parece ser significativamente diferente do perigo deste micro-organismo produzir toxinas em produtos embalados aerobicamente (HOLLEY, GILL, 2005)

De acordo com Church (1994), tem havido interesse sobre a habilidade de outros patógenos psicrotróficos, como os dos gêneros Aeromonas, Yersinia e Listeria, de crescerem em produtos embalados em EAM. L. monocytogenes, $Y$. enterocolítica e $A$. hidrophila são mais competitivos que outros psicrotróficos e, consequentemente, uma concentração de $40 \%$ de $\mathrm{CO}_{2}$ é requerida para sua inibição efetiva. Estes micro-organismos representam perigo em potencial para a saúde dos consumidores de carnes embaladas a vácuo. L. monocytogenes e Y. enterocolitica podem crescer em altas concentrações de $\mathrm{CO}_{2}$, até $75 \%$ em carnes "Dark, Firm and Dry" (DFD) (CHURCH, 1995).

O que distingue os alimentos preservados em atmosfera modificada dos demais alimentos refrigerados não é o fato de permitir o crescimento de patógenos, mas sim o fato de não permitir que micro-organismos deteriorantes cresçam conjuntamente com os patogênicos, o que tornaria o alimento inaceitável para o consumidor. Portanto, faz-se necessário mais pesquisas a fim de se determinar a relação entre deterioração e patogenicidade, associadas a previsões estatísticas, que permitam avaliar os verdadeiros riscos de enfermidades alimentares. Essa situação provavelmente representa a maior vulnerabilidade dos sistemas com EAM (ZEPKA, 2009).

1 ZURER, P.S. Food Irradiation. Chemical \& Engineering News, v. 64, n. 18, p. 46, 1986.

Rev. Acad., Ciênc. Agrár. Ambient., Curitiba, v. 8, n. 4, p. 437-448, out./dez. 2010 


\section{Considerações finais}

A embalagem em atmosfera modificada consiste na substituição dos gases no interior da embalagem por uma mistura predeterminada. O efeito bacteriostático do $\mathrm{CO}_{2}$ ainda não é bem compreendido, mas é sabido que esse gás aumenta a fase de adaptação e reduz a taxa de crescimento dos micro-organismos, proporcionando, assim, um aumento na validade comercial do alimento. A técnica pode ser feita ativa ou passivamente. A escolha do material de envase, da mistura de gases e de suas proporções vai depender, principalmente, do tipo de alimento e dos mecanismos de deterioração. Se o alimento não respira e sua deterioração ocorre pelo crescimento de micro-organismos deteriorantes, como nas carnes e derivados, a mistura ideal deve possuir altas concentrações de $\mathrm{CO}_{2}$ e o filme de embalagem deve ter pouca permeabilidade aos gases. Porém, no caso de frutas e vegetais, que são alimentos que continuam respirando após a colheita, a técnica de embalagem mais utilizada é a passiva, que permite o equilíbrio entre os gases $\mathrm{CO}_{2}$ e $\mathrm{O}_{2}$ no interior da embalagem, e o filme deve possuir permeabilidade intermediária aos gases para possibilitar a troca gasosa. Os possíveis riscos associados ao uso da EAM em alimentos estão relacionados com a ausência de $\mathrm{O}_{2}$ no interior da embalagem, que poderia propiciar o desenvolvimento de bactérias anaeróbias patogênicas em detrimento das aeróbias deteriorantes, com a manutenção de seu aspecto de frescor. Assim, o alimento não seria rejeitado pelos consumidores, representando um risco em potencial para a saúde coletiva. Entretanto, mais estudos devem ser realizados com o intuito de verificar os verdadeiros riscos da EAM em alimentos.

\section{Referências}

AMANATIDOU, A. et al. High oxygen and high carbon dioxide modified atmospheres for shelf-life extension of minimally processed carrots. Journal of Food Science, v. 65, n. 1, p. 61-66, 2000.

BLAKISTONE, B. A. Principles and applications of modified atmosphere packaging of Foods. New York: Chapman \& Hall, 1999. Disponível em: <http://books.google.com.br/books?id=78sOfd9OgXYC\&pg=PA1\&dq $=$ BLAKISTONE,+ B. + A. + Principles + and + Applications + of + Modified + Atmosphere + Packaging + of + Foods.\&hl $=$ pt-BR\&ei=usrmTM2YJoOKlweU_922Cw\&sa $=$ X\&oi=book_result\&ct $=$ result\&resnum $=1 \& v e d=0 C C s Q 6 A E w A A$ $\#_{\mathrm{v}}=$ onepage\&q=BLAKISTONE $\% 2 \mathrm{C} \% 20 \mathrm{~B} . \% 20 \mathrm{~A} . \% 20$ Principles $\% 20$ and $\% 20$ Applications $\% 20$ of $\% 20$ Modified $\% 20$ Atmosphere\%20Packaging\%20of\%20Foods.\&f=false>. Acesso em: 30 mar. 2010.

BRODY, A. L. El mercado. In: PARRY, R. T. Envasado de los alimentos en atmósfera modificada. Zaragoza: Acribia, 1995. p. 32-55.

CHURCH, N. Developments in modified-atmosphere packaging and related technologies. Trends in Food Science e Technology, v. 5, p. 345-352, 1994.

CHURCH, I. J.; PARSONS, A. L. Modified atmosphere packaging tecnology: a review. Journal of the Science of Food and Agriculture, v. 67, p. 143-152, 1995.

CONCEIÇÃO, M. P. J. Avaliação de sistemas de embalagem e condições de comercialização de carne bovina moída em atmosfera modificada. 2002. 134 f. Tese (Doutorado em Tecnologia de Alimentos) - Universidade Estadual de Campinas, São Paulo, 2002.

DAY, B. P. F. Frutas y hortalizas. In: PARRY, R. T. Envasado de los alimentos em atmosfera modificada. Madrid: A. Madrid Vicente, 1993. p. 133-154.

DEVLIEGHERE, F. et al. Modified atmosphere packaging (MAP). In: HENRY, C. J. K.; CHAPMAN, C. The nutrition handbook for food processors. 2002. Disponível em: <http://books.google.com.br/books?id=MbVtx091tCU C\&pg $=$ PA171\&dq=DEVLIEGHERE, + F. + et + al. + Modified + atmosphere+packaging $+\% 28 \mathrm{MAP} \% 29 .+$ In: +++ HE $\mathrm{NRY},+$ C. + J. + K. $\% 3 \mathrm{~B}+\mathrm{CHAPMAN},+\mathrm{C} .+$ The + nutrition + handbook + for + food + processors. $+2002 \& \mathrm{hl}=\mathrm{pt}-\mathrm{BR} \& \mathrm{ei}=$ B87mTPKuGYOBlAfD1fTQCw\&sa $=$ X\&oi=book_result\&ct $=$ result\&resnum $=1 \& v e d=0$ CCkQ6AEwAA\# ${ }_{\mathrm{v}}=$ onepag

Rev. Acad., Ciênc. Agrár. Ambient., Curitiba, v. 8, n. 4, p. 437-448, out./dez. 2010 
e\&q=DEVLIEGHERE $\% 2 C \% 20 \mathrm{~F} . \% 20$ et $\% 20$ al. $\% 20$ Modified $\% 20$ atmosphere $\% 20$ packaging $\% 20 \% 28 \mathrm{MAP} \% 29 . \% 20$ In $\% 3$ A $\% 20 \% 20 \% 20$ HENRY $\% 2$ C $\% 20$ C. $\% 20 \mathrm{~J} . \% 20 \mathrm{~K} . \% 3 \mathrm{~B} \% 20 \mathrm{CHAPMAN} \% 2 \mathrm{C} \% 20 \mathrm{C} . \% 20$ The $\% 20$ nutrition $\% 20$ handbook $\% 20$ for $\% 20$ food $\% 20$ processors. $\% 202002 \& f=$ false $>$. Acesso em: 31 mar. 2010.

EILERT, S. J. New packaging technologies for the 21st century. Meat Science, v. 71, n. 1, p. 122-127, 2005.

FANTUZZI, E. et al. Microbiota contaminante em repolho minimamente processado. Ciência e Tecnologia de Alimentos, v. 24, n. 2, p. 207-211, 2004.

FINNE, G. Modified-and controlled-atmosphere storage of muscle foods, Food Technology, v. 36, n. 2, p. 128-133, 1982.

FLOROS, J. D.; MATSOS, K. I. Introduction on modified atmosphere packaging. In: HAN, J. H. Innovations in food packaging. 2005. Disponível em: <http://books.google.com.br/books?id=MbVtx091tCUC\&pg=PA103\&dq=HA $\mathrm{N},+$ J.+H.+Innovations + in + food + packaging. $+2005 \& \mathrm{hl}=$ pt-BR\&ei=wM_mTJTKHsWblgfDn7iFDA\&sa=X\&oi=bo ok_result\&ct=result\&resnum=1\&ved=0CC8Q6AEwAA\#v=onepage\&q\&f=false $>$. Acesso em: 30 mar. 2010.

GENIGEORGIS, C. Microbial and safety implications of the use of modified atmospheres to extend the storage life of fresh meat and fish. International Journal of Food Microbiology, v. 1, p. 237-251, 1895.

GREENGRASS, J. Films para envasado en atmósfera modificada. In: PARRY, R.T. Envasado de los alimentos em atmosfera modificada. Madrid: A. Madrid Vicente, 1993. p. 79-118.

HASTINGS, M. J. Maquinaria de empaquetado. In: PARRY, R.T. Envasado de los alimentos em atmosfera modificada. Madrid: A. Madrid Vicente, 1993. p. 56-78.

HINTLIAN, C. B.; HOTCHKISS, J. H. The safety of modified atmosphere packaging: a review. Food Technology, v. 40, p. 70-76, 1986.

HOLLEY, R. A.; GILL, C. O. Usos da embalagem em atmosfera modificada para carnes e produtos cárneos. Palestra. In: CONGRESSO BRASILEIRO DE CIÊNCIA E TECNOLOGIA DE CARNES, 3., 2005, Campinas. Anais... Campinas: CBCTC, 2005.

JAY, J. M. Microbiologia de alimentos. 6. ed. Porto Alegre: Artmed, 2005.

JACXSENS, L. et al. Effect of high oxygen modified atmosphere packaging on microbial growth and sensorial qualities of fresh-cut produce. International Journal of Food Microbiology, v. 71, n. 2/3, p. 197-210, 2001.

JIMÉNEZ, S. M. et al. Spoilage microflora in fresh chicken breast stored at $4{ }^{\circ} \mathrm{C}$ : influence of packaging methods. Journal of Applied Microbiology, v. 83, p. 613-618, 1997.

LEON, G. et al. Modified-atmosphere packaging of produce. In: RAHMAN, S. Handbook of food preservation. 1999. Disponível em: <http://books.google.com.br>. Acesso em: 30 mar. 2010.

MANO, S. B. et al. Aumento da vida útil e microbiologia da carne suína embalada em atmosfera modificada. Ciência e Tecnologia de Alimentos, v. 22, n. 1, p. 1-10, 2002.

NUNES, E. et al. Qualidade de mandioquinha-salsa minimamente processada e armazenada sob atmosfera modificada. Ciência Rural, v. 39, n. 7, p. 2185-2190, 2009.

OORAIKUL, B. Modified atmosphere packaging (MAP). In: ZEUTHEN, P.; BØGH-SØRENSEN, L. Food preservation techniques. 2003. Disponível em: <http://books.google.com.br/books?id=TdQtFQZ5XCQC\&pg=PR $9 \& \mathrm{dq}=$ OORAIKUL, + B. + Modified + atmosphere+packaging $+\% 28 \mathrm{MAP} \% 29 .+$ In: + ZEUTHEN,+ P. $\% 3 \mathrm{~B}+\mathrm{B} \% \mathrm{C} 3 \%$ 98GH-S\%C3\%98RENSEN,+L.+Food + preservation+techniques. $+2003 \& \mathrm{hl}=$ pt-BR\&ei=kNXmTJOqNIaBlAfs9tj $\mathrm{MCw \& sa}=\mathrm{X} \&$ oi $=$ book_result\&ct=book-thumbnail\&resnum $=1 \& v e d=0 C C s Q 6 w E w A A \#_{\mathrm{v}}=$ onepage\&q\&f$=$ false $>$. Acesso em: 30 mar. 2010.

ORDONEZ, J. A. et al. Microbial and physicochemical modifications of hake (Merlucccius merluccius) stakes stored under carbon dioxide enriched atmosphere. Journal of the Science of Food and Agriculture, v. 80, p. 1831-1840, 2000.

Rev. Acad., Ciênc. Agrár. Ambient., Curitiba, v. 8, n. 4, p. 437-448, out./dez. 2010 
PARRY, R. T. Introduccíon. In: PARRY, R. T. Envasado de los alimentos em atmosfera modificada. Madrid: A. Madrid Vicente, 1993. p. 13-31.

PATSIAS, A. et al. Shelf-life of a chilled precooked chicken product stored in air and under modified atmospheres: microbiological, chemical, sensory attributes. Food Microbiology, v. 23, p. 423-429, 2006.

PEREIRA, A. S. C. Novas tecnologias de embalagens para produtos cárneos. 2005. Disponível em: < http://www. beefpoint.com.br>. Acesso em: 29 mar. 2009.

RIQUELME, F. et al. Packaging of fruits and vegetables: recent results. In: MATHLOUTHI, M. Food Packaging and Preservation. 1994. Disponível em: <http://books.google.com.br>. Acesso em: 30 mar. 2010.

ROBERTSON, G. L. Modified atmosphere packaging. In: ROBERTSON, G. L. Food packaging: principles and practice. 2006. Disponível em: <http://books.google.com.br>. Acesso em: 12 mar. 2010.

ROSA, A. F. Estudo proteômico do efeito da atmosfera modificada na estabilidade da cor e na vida útil da carne suína acondicionada em embalagens de transporte tipo masterpack sob refrigeração. 2009. 103 f. Tese (Doutorado em Zootecnia) - Faculdade de Zootecnia e Engenharia de Alimentos, Universidade de São Paulo, São Paulo, 2009.

ROVERSI, R. M.; MASSON, M. L. Qualidade da alface crespa minimamente processada acondicionada em atmosfera modificada. Ciência e Agrotecnologia, v. 28, n. 4, p. 823-830, 2004.

SALGADO, R. L. Efeito da embalagem em atmosfera modificada sobre a conservação de pargo (Pagruspagrus). 2006. 67 f. Dissertação (Mestrado em Higiene Veterinária e Processamento Tecnológico de Produtos de Origem Animal) Faculdade de Veterinária, Universidade Federal Fluminense, Niterói, RJ. 2006.

SANTOS, J. C. B. et al. Avaliação da qualidade do abacaxi "Pérola" minimamente processado armazenado sob atmosfera modificada. Ciência e Agrotecnologia, v. 29, n. 2, p. 353-361, 2005.

SARANTÓPOULOS, C. I. G. L. Embalagens para vegetais minimamente processados - Fresh Cut. Boletim de Tecnologia e Desenvolvimento de Embalagens, v. 9, n. 5, p. 4, 1997.

SAUCIER, L. et al. Shelf life of ground poultry meat stored under modified atmosphere. Poultry Science, v. 79, p. $1851-1856,2000$.

SMITH, J. P. et al. Developments in food packaging technology. Part II: storage aspects. Trends in Food Science e Technology, v. 1, p. 111-118, 1990.

STROTMANN, C. et al. Effect of different concentrations of carbon dioxide and oxygen on the growth of pathogenic Yersinia enterocolitica 4/O:3 in ground pork packaged under modified atmospheres. Journal of Food Protection, v. 71, n. 4, p. 845-849, 2008.

VILAS BOAS, B. M. et al. Qualidade pós-colheita de melão ‘Orange Flesh’ minimamente processado armazenado sob refrigeração e atmosfera modificada. Revista Brasileira de Fruticultura, v. 26, n. 3, p. 438-440, 2004.

ZEPKA,M.Atmosfera Modificada/Atmosfera Controlada. Disponível em: < http:/ /www.furg.br/portaldeembalagens/ quatro/atm_modific.html>. Acesso em: 14 set. 2009.

Recebido: 20/06/2010

Received: 06/20/2010

Aprovado: 22/09/2010

Approved: 09/22/2010

Rev. Acad., Ciênc. Agrár. Ambient., Curitiba, v. 8, n. 4, p. 437-448, out./dez. 2010 